Bryant University

Bryant Digital Repository

$11-28-2020$

\title{
Can I Be Me With You at Work? Examining Relational Authenticity and Discretionary Behaviors in the Workplace
}

\author{
Kathryn Ostermeier \\ Bryant University, kostermeier@bryant.edu \\ Michele N. Medina-Craven \\ Mississippi State University \\ Kerri M. Camp \\ University of Texas at Tyler \\ Sara E. Davis \\ Mississippi State University
}

Follow this and additional works at: https://digitalcommons.bryant.edu/apjou

Part of the Other Psychology Commons

\section{Recommended Citation}

Ostermeier, Kathryn; Medina-Craven, Michele N.; Camp, Kerri M.; and Davis, Sara E., "Can I Be Me With You at Work? Examining Relational Authenticity and Discretionary Behaviors in the Workplace" (2020). Applied Psychology Journal Articles. Paper 48.

https://digitalcommons.bryant.edu/apjou/48

This Article is brought to you for free and open access by the Applied Psychology Faculty Publications and Research at Bryant Digital Repository. It has been accepted for inclusion in Applied Psychology Journal Articles by an authorized administrator of Bryant Digital Repository. For more information, please contact dcommons@bryant.edu. 


\title{
Can I be me with you at work? Examining relational authenticity and discretionary behaviors in the workplace
}

\begin{abstract}
Management scholars have long been interested in the topic of authenticity in the workplace, evidenced by the history of scholarship on authentic leadership and the many new authenticity constructs that have emerged. In this paper, we take a narrower view of authenticity and focus on relational authenticity in the workplace, which we define as being genuine in workplace relationships. Adapting a validated relational authenticity scale to the organizational context, we explore the ways in which feeling authentic in workplace relationships has ramifications for discretionary behaviors. Specifically, we build on belongingness theory to posit that relational authenticity will result in an increase in engagement in both altruistic and sportsmanship behaviors. We also explore the moderating effect of proactive personality on these relationships. Results from our two-sample study $(N=352 ; 500)$ indicate that relational authenticity is positively associated with engagement in both altruistic and sportsmanship behaviors.
\end{abstract}

Keywords: authenticity, workplace relationships, proactive personality, organizational citizenship behaviors 


\section{INTRODUCTION}

The idea of authenticity has existed for centuries. Authenticity, which is defined (at the individual-level) as the subjective experience of alignment between one's inward sense of self and one's outward expressions of self (Caza, Moss, \& Vough, 2017), has been extoled, explored, and debated by both philosophers and playwrights and, more recently, by psychologists such as Rogers and Maslow (Harter, 2002; Novicevic, Harvey, Ronald, \& Brown-Radford, 2006). Indeed, authenticity became an ideal that Western culture has strongly embraced (Liedtka, 2008; Roberts, Cha, Hewlin, \& Settles, 2009).

This fascination with authenticity has cascaded into the business world, sparking interest in authenticity within the workplace. Scholars have theorized about why this topic has become of interest to employees and their organizations. Some suggestions include scandals involving dishonest leadership (Gardner, Cogliser, Davis, \& Dickens, 2011) and, consequently, how authenticity has become the gold standard for leadership within organizations (Carroll, 2015). It is no surprise then that the focus of research on authenticity in the workplace has been on authenticity in leadership, through the construct of authenticity leadership, although scholars recently have begun to explore other configurations of authenticity in organizations, such as authenticity in the workplace (van den Bosch \& Taris, 2014), authentic personality (Wood, Linley, Maltby, Baliousis, \& Joseph, 2008), and authenticity of positive displays (Grandey, Fisk, Mattila, Jansen, \& Sideman, 2005). Additional authenticity constructs include self-verification striving (Cable \& Kay, 2012) and role authenticity (Sheldon, Ryan, Rawsthorne, \& Ilardi, 1997). However, authenticity has also been explored through inauthenticity constructs such as emotional labor (Brotheridge \& Grandey, 2002), facades of conformity (Hewlin, 2009), and impression management (Bolino \& Turnley, 1999). 
Holistically, this body of work indicates that individuals who feel authentic at work are more likely to have increased well-being (e.g., Emmerich \& Rigotti, 2017; Goldberg \& Grandey, 2007; Hewlin, 2009), are more likely to feel like they belong at their organization (Hewlin, Kim, \& Song, 2016; van den Bosch \& Taris, 2014), and are more motivated to work (Cable, Gino, \& Staats, 2013; Hewlin, Dumas, \& Burnett, 2017; Leroy, Anseel, Dimitrova, \& Sels, 2013). A recent review by Cha and colleagues (2019, p. 643) also notes that "an accumulation of empirical studies pointed to consistent positive associations between experienced authenticity and the desirable internal states of well-being and work engagement, as well as positive effects of externally-perceived authenticity on performance, image, and career outcomes."

While these constructs clearly demonstrate that being authentic at work matters for the individuals themselves, does authenticity at work actually benefit the organization? Although the Cha et al. (2019) review noted that there were some positive associations between being perceived as authentic by others and some performance outcomes, overall, less research has focused on the relationship between authenticity in the workplace and actual performance. Exceptions to this include Knoll and van Dick (2013), who explored the relationship between authenticity and silence in the workplace, and the authenticity leadership literature as a whole, which, for example, has found that authentic leadership positively affects an individual's propensity to engage in organizational citizenship behaviors (OCBs), especially those that are organizationally-directed (Valsania, León, Alonso, \& Cantisano, 2012; Wong, Laschinger, \& Cummings, 2010). While this research provides preliminary evidence that authenticity is beneficial for organizations, these findings are limited. First, in Knoll and van Dick's (2013) work, authenticity is only linked to employee silence and prohibitive voice which, while discretionary behaviors, are only a small subset. Moreover, in their operationalization of 
authenticity, the authors focus solely on the individual - that they know themselves and stand for their personal beliefs. We suggest that this view of authenticity, which is focused solely on the individual (or follower, in the case of the authentic leadership literature), does not fully capture the complexity of authenticity in the workplace. Accordingly, we theorize that an important facet of authenticity in the workplace incorporates relationships with others. Second, in the authentic leadership literature, there is an implicit assumption that authenticity is always a good thing due to the positive conceptualization of the construct (e.g., the "best self" conceptualization) and its operationalization. In contrast, we view authenticity in more neutral terms - as something that can be both positive and negative (e.g., a "true self" conceptualization). Thus, we argue for a more nuanced conceptualization of authenticity that both captures the relational element of the construct and takes a true self perspective.

To this end, we explore a promising new conceptualization of authenticity at work relational authenticity, which refers to authenticity in relationships, taking a true self perspective. Relational authenticity is distinct from other authenticity constructs as it focuses on the perceived relationship that an individual has with others in the workplace (i.e., a relational orientation), with a true self perspective. In other words, an individual who feels that they can be themselves (including both positive and negative traits, dispositions, attitudes, etc.) with the people they work with, will perceive more authenticity in their relationships at work (i.e., high relational authenticity). This construct is different than relational transparency (a dimension of authentic leadership), for example, as relational transparency is specifically focused on the leader-follower relationship. Additionally, relational authenticity is conceptualized as a separate, distinct, and unidimensional construct rather than part of a higher order, multidimensional construct that holistically takes a "best self" approach to authenticity. 
We examine the link between relational authenticity and discretionary behaviors, such as OCBs which, according to Rotundo and Sackett (2002), is one of the three dimensions of organizational performance. Using the need to belong theory (Baumeister \& Leary, 1995), we posit that individuals who feel more authenticity in their workplace relationships will engage in more discretionary behaviors, such as OCBs, as relational authenticity satisfies the innate need of individuals to have genuine, interpersonal relationships. Consequently, individuals who have this need met will have more energy to direct into activities for which they are not necessarily paid, but ultimately support the organization's functioning.

\section{Authenticity and the Need to Belong}

Authenticity has been discussed and debated throughout multiple disciplines over many centuries. As such, it has many different conceptualizations. The overarching view, however, is that authenticity is about being true to yourself (e.g., van den Bosch \& Taris, 2014). Relational authenticity is an exploration of authenticity in the context of relationships and is based on the work of Kernis (2003), who suggested that authenticity is composed of four components: awareness, unbiased processing, action, and relational orientation. We believe that the future of authenticity lies in the relational component, which Kernis (2003) describes as being genuine and not fake in one's relationships. Following Kernis (2003), we define relational authenticity as how true to oneself (genuine) an individual is in their relationships with coworkers and supervisors. Additionally, as Cha and colleagues (2019) argue in their review of authenticity that authenticity can be categorized into experienced authenticity (or self-rated authenticity) and externally-perceived authenticity (or other-rated authenticity). Because we are exploring an individual's perception of how genuine they can be with their coworkers and supervisors, we take an experienced authenticity approach to capturing relational authenticity. Next, we are 
conceptualizing relational authenticity as a characteristic of the individual within their specific organizational relational context, rather than a personality trait that is stable, consistent, and enduring across contexts (cf. Conley, 1985; McCrae \& Costa, 1994).

In addition to defining authenticity, researchers have studied how authenticity can affect life outcomes. Authenticity is linked to greater psychological functioning and well-being (Sheldon \& Kasser, 1995), including life satisfaction and positive self-esteem levels (Kernis \& Goldman, 2006). And, in the workplace, authenticity has also been linked to increased engagement. Combined, this evidence suggests that authenticity might also have positive effects on other organizational outcomes (such as engagement in discretionary behaviors) when individuals feel that they can be authentic regarding their workplace relationships. Thus, we contend that these beneficial effects of authenticity suggest that there are important implications for individuals who can be their true selves in their relationships with others (i.e., relational authenticity) at work. We posit that the benefits of authenticity, and specifically relational authenticity, are accrued through it satisfying the innate, even evolutionary, need of every individual to belong (Baumeister \& Leary, 1995; Caporael \& Brewer, 1995; Stevens \& Fiske, 1995). The need to belong can be defined as the need by all individuals to maintain strong relationships with other people. The importance of our connection to others is highlighted by research which finds that people are reluctant to break social bonds, even when these bonds are harmful (Strube, 1988). Indeed, social bonds are important: forming and maintaining social bonds is positively associated with increased happiness and positive life outcomes (Baumeister \& Twenge, 2003; Myers, 1992).

While the loss of a relationship can be replaced with another relationship, new relationships take time and the benefits of social contact, such as a sense of belonging, are only 
attained in long-term relationships (Baumeister \& Leary, 1995). According to Baumeister and Leary (1995), the need to belong has two main features, namely that individuals need frequent interactions with other people and, second, that the interpersonal relationships formed are characterized by stability, affective concern, and continuity. When individuals feel that they can be their true selves in their workplace relationships, we theorize that this will help cement these workplace relationships by creating an authentic and firm foundation over time. This is tangentially supported by research which suggests that people become truer to themselves over time as they mature in their career (Shamir \& Eilam, 2005). Moreover, previous research demonstrates that age differences influences perceptions of authenticity (e.g., Grayson \& Shulman, 2000; Lehman, O’Connor, Kovacs, \& Newman, 2019). Hence, when people are authentic in their relationships, this would increase cohesion in their work social groups and increase their sense of belonging to this group. Further, we suggest that individuals who feel relationally authentic in their workplace relationships will seek to preserve these work environments that fulfill this important evolutionary need to belong.

\section{Relational Authenticity and OCBs}

Organizational citizenship behaviors (OCBs) have been a popular topic of research interest throughout the decades, primarily due to the belief that these extra-role behaviors enhance organizational effectiveness (Podsakoff \& MacKenzie, 1997). Comprised of the dimensions of altruism, sportsmanship, civic virtue, and conscientiousness, OCBs encompass a variety of extra-role behaviors in the workplace. Additionally, OCBs are one of the three broad performance domains according to empirical evidence (Rotundo \& Sackett, 2002). As a result, researchers have explored the ways in which personality (Ball, Trevino, \& Sims, 1994;

Bettencourt, Gwinner, \& Meuter, 2001), task (Bateman \& Organ, 1983), organizational (Guzman 
\& Espejo, 2015), and leadership traits (Babcock-Roberson \& Strickland, 2010) encourage employees to engage in OCBs. Despite the multitude of research on OCBs, questions regarding why employees engage in these discretionary behaviors remain.

While recent research has focused on a within-person view of OCB engagement (e.g., Trougakos, Beal, Cheng, Hideg, \& Zwrig, 2015), more work is needed to explain the betweenperson variance in OCB engagement. To this aim, some research has explored the role of relationship quality, such as trust and leader-member exchange with the dimensions of OCBs (e.g., Asgari, Silong, Ahmad, \& Samah, 2008; Deluga, 1994; Rubin, Bommer, \& Bachrach, 2010; Wat \& Shaffer, 2005). Likewise, in this study, we seek to explore how relational authenticity in the workplace can explain between-person variance in these discretionary behaviors. Drawing from belongingness theory (Baumeister \& Leary, 1995), we posit that individuals will be more likely to engage in behaviors that support the functioning of the organization, despite a lack of extrinsic organizational rewards for doing so, when they have strong, authentic relationships at work. Specifically, we believe that relational authenticity will foster these behaviors because individuals will seek to support the environment in which their interpersonal relationships thrive, as these relationships satisfy an innate need of individuals. Additionally, we posit that individuals are more likely to behave altruistically towards and engage in sportsmanship behaviors for individuals with which they have positive, authentic relationships. This is supported by the research on the positive effect that workplace friendships have on interpersonal citizenship behavior, a form of OCB (Bowler \& Brass, 2006). Therefore, we predict:

Hypothesis 1a: Relational authenticity is positively related to altruism (OCBs). Hypothesis 1b: Relational authenticity is positively related to sportsmanship (OCBs). 


\section{Proactive Personality, Altruism, and Sportsmanship}

Theorists believe the person-environment relationship is characterized by reciprocal causal links (Magnusson \& Endler, 1977). This means the person, environment, and behavior mutually and continuously influences each other (Bandura, 1986). In other words, people can intentionally and directly change their current circumstances, social or nonsocial (Buss, 1987). Thus, while we posit that relational authenticity positively influences engagement in OCB dimensions, such as altruism and sportsmanship, through engendered feelings of belonging, we understand that individual differences will play a role in the strength of this relationship. And, while other interesting individual differences exist that potentially could affect the strength of the relationship between relational authenticity and OCB engagement, proactive personality is especially compelling in that it "identifies differences among people in the extent to which they take action to influence their environments" (Bateman \& Crant, 1993, p. 103). In other words, it accounts for the differences among individuals in how much relational authenticity might actually influence their engagement in extra-role or discretionary behaviors, based on their belief that they can influence their environment. Consequently, we examine the moderating effect of proactive personality on the relationship between relational authenticity and OCB engagement.

Based on a meta-analysis, proactive personality has been shown to be related to a variety of desirable individual and organizational outcomes (Fuller \& Marler, 2009). Specifically, proactive personality has a positive effect on work performance due to the development of social networks (Thompson, 2005), as well as being linked to charismatic leadership (Crant \& Bateman, 2000), career success (Seibert, Kraimer, \& Liden, 2001), a college graduate’s successful job search (Brown, Cober, Kane, Levy, \& Shalhoop, 2006), and entrepreneurial intentions (Crant, 1996). Relevant to this study, Li, Liang, and Crant (2010) found that proactive 
personality influences the amount of OCBs in which an individual engages. We extend this finding to argue that proactive personality should also serve to enhance the relationship between relational authenticity and OCBs, as an inclination towards proactivity should result in individuals who feel that they can be genuine in their workplace relationships engaging in more discretionary behaviors in order to preserve the organizational environment that fulfills the important psychological need to belong than individuals who also feel the same but do not believe they can change their environment (i.e., low proactive personality). In other words, individuals who are proactive believe they can change their environments and are more likely to engage in discretionary behaviors to preserve it when they feel relationally authentic. Accordingly, proactive personality should enhance the relationship between relational authenticity and OCB engagement by strengthening this positive relationship. Thus, we predict:

Hypothesis 2a: Proactive personality will positively moderate the relationship between relational authenticity and altruism.

Hypothesis 2b: Proactive personality will positively moderate the relationship between relational authenticity and sportsmanship.

A visual representation of our model and hypotheses is displayed in Figure 1.

[Figure 1 about here]

\section{METHOD}

\section{Research Design}

We explore the concept of relational authenticity by adapting a measure used to assess relational authenticity from the counseling psychology literature. Using a two-study, constructive replication design (Lykken, 1968), we test our theoretical model using two samples of working adults. The aim of Study 1, using a sample of students who were currently enrolled in full-time work $(N=352)$, hereafter the student employee sample, was to conduct initial validation of the 
measure we adapted for assessing relational authenticity, as well as for conducting an initial test of the hypotheses. Study $2(N=500)$, using a sample of full-time retail employees, referred to as the retail employee sample, was designed to conduct an additional test of the hypotheses.

\section{STUDY 1}

\section{Participants and Procedure}

We surveyed undergraduate students from a large public university in the southwestern United States who completed online self-reports of relational authenticity, proactive personality, and OCBs. This context allowed us to sample a large pool of individuals with work experience that would have the ability to answer questions about their work environment and current organization. As compensation for their participation, participants received extra credit in their courses. Overall, the online survey was distributed to 841 individuals, with 552 responding (65.6\% response rate). Of those who responded, 140 were eliminated for not completing the entire survey. Respondents who indicated that they were not currently working (i.e., selected "student only" when asked about their current job) were excluded from the study, eliminating 60 responses. After eliminating these respondents, the student employee sample size is 352 (42\% response rate). This sample was $42 \%$ male, with a range of $18-53$ years, with an average age of $24.85(\mathrm{SD}=6.80)$, and current job tenure ranging from less than one year $(37.78 \%), 1-3$ years (40.91\%), 4-6 years (14.2\%), 7-10 years (3.69\%) and over 10 years (3.41\%). Current enrollment status indicated that the majority of the students were juniors (32.39\%) and seniors (54.83\%). Although this sample is relatively young, prior research suggests that young adults are able to form authentic relationships with others in a therapy session over a relatively short period of time (Kolden, Klein, Wang, \& Austin, 2011); therefore, it follows that these young adults should also be able to form authentic relationships within a workplace context. 


\section{Measures}

All measures were based on a 5-point Likert scale ranging from strongly disagree (1) to strongly agree (5) with neither agree nor disagree (3) as the midpoint.

Relational Authenticity. While scales on authenticity exist (e.g., Wood et al., 2008), only the Goldman and Kernis (2001) scale attempted to measure relational authenticity. While Goldman and Kernis' (2001) scale is useful in that it explores the multidimensionality of authenticity, we suggest that the relational authenticity dimension scale items reflect the construct of self-monitoring (Snyder \& Gangestad, 1986) rather than our definition of relational authenticity. Thus, we investigated other authenticity scales that referenced relationships to which we could adapt to the organizational context. In the adjacent counseling psychology literature, Lopez and Rice (2006) developed and validated a scale for authenticity in intimate partner relationships. While the purpose of therapy and work-life are different, previous researchers demonstrated that therapy can assist employees to resolve their work-family conflict, thus ensuring that employees are satisfied on both fronts (cf. Carroll, Hill, Yorgason, Larson, \& Sandberg, 2013; Frone, Russell, \& Cooper, 1992; Tatman, Hovestadt, Yelsma, Fenell, \& Canfield, 2006). Similarly, in their study of transactive memory, Wegner and colleagues (1991) have established the significance of intimate partner relationships in a work context. Therefore, we believe that adapting this scale to the organizational context is appropriate and, when adapted, these items reflect our conceptualization of relational authenticity. Accordingly, we adapted 7 items from the Lopez and Rice (2006) scale to fit workplace relationships (some items from the Lopez and Rice scale did not translate to a workplace context, such as "I feel free to reveal the most intimate parts of myself to my partner"). The Cronbach's alpha for the 7 items 
for our adapted measure is 0.83 . A sample item includes "Sometimes I feel like I am two different people - one when I'm at work and one when I'm by myself (reverse-coded)."

Organizational Citizenship Behaviors. We used 12 items from MacKenzie, Podsakoff, and Fetter (1993). We used the dimensions of sportsmanship and altruism as proxies for OCBs, due to the poor inter-item reliability of the other dimensions. According to Organ (1988), altruism refers to the helping of others with an organizationally-relevant task and sportsmanship is the willingness of an employee to work under less than ideal circumstances without complaining. A sample item for altruism is "I am always ready to help or to lend a helping hand to those around me." A sample item for sportsmanship is "I tend to make "mountains out of molehills' (make problems bigger than they are) (reverse-coded)." The Cronbach's alpha for the student employee sample is 0.80 for the 3 sportsmanship items and 0.69 for the 3 altruism items.

Proactive Personality. We used 10 items from Bateman and Crant's (1993) proactive personality scale. The Cronbach's alpha for these 10 items from the student employee sample is 0.89. A sample item is "No matter what the odds, if I believe in something, I will make it happen."

Controls. We controlled for age, gender, and current job tenure as previous research demonstrated that each may be related to dimensions of OCBs (Chiu \& Tsai, 2006; Kidder, 2002; Kuehn \& Al-Busaidi, 2002).

[Tables 1, 2, \& 3 about here]

\section{Analyses}

We first subjected all items to a confirmatory factor analysis (CFA) using IBM SPSS AMOS. The fit indices for the 4-factor structure for the student employee sample $\left(X^{2}=346.33\right.$, $d f=215, p<0.000, \mathrm{CFI}=0.96, \mathrm{GFI}=0.92, \mathrm{AGFI}=0.90, \mathrm{SRMR}=0.05$, and $\mathrm{RMSEA}=0.04)$ 
were acceptable (Hu \& Bentler, 1999). The CFA measurement model is displayed in Table 1. Means, standard deviations, and correlations among the variables are displayed in Table 2. We further assessed convergent and discriminant validities using composite reliability (CR), average variance extracted (AVE), maximum shared variance (MSV), and maximum reliability $(\operatorname{MaxR}(\mathrm{H}))$. As displayed in Table 3, the thresholds for CR (greater than 0.70), MSV $(\mathrm{MSV}<$ $\mathrm{AVE}$ ), and $\operatorname{MaxR}(\mathrm{H})$ (greater than 0.80) is acceptable for all variables (Hair, Black, Babin, \& Anderson, 2010; Hancock, 2001). While AVE is just below the threshold of 0.50 for proactive personality and relational authenticity, as argued by Malhotra and Dash (2011), AVE is a stricter measure of convergent validity and thus validity can be established through CR alone. Moreover, as Hancock (2001) contends, $\operatorname{Max}(\mathrm{H})$ is a more robust measure of reliability than $\mathrm{CR}$. Therefore, we contend that our measures have reliability and validity.

Before proceeding to test the hypotheses, we conducted a common method variance test. We compared the unconstrained common method factor model to the fully (zero) constrained common method factor (Podsakoff, MacKenzie, \& Podsakoff, 2012). The test resulted in the $X^{2}$ being significantly different (difference in $X^{2}=107.6, d f=23, p<0.01$ ). Therefore, there is significant shared variance in the model, which resulted in our retaining the common latent factor for the remaining analyses.

To test the hypothesized model, we used the Preacher and Hayes $(2004,2008)$ method. This regression-based approach allowed us to test both the direct and indirect relationships in the model, and this method is in step with the recent advancements in the statistical methods literature (Hayes, 2009). Following Preacher and Hayes (2008), we utilized the bootstrapping procedures with 5,000 samples with a 95\% confidence interval. We utilized Version 3 of the Preacher and Hayes PROCESS macro (cf. Hayes, 2018) and ran two iterations of Model 1 in 
order to assess both dependent variables (sportsmanship and altruism). We controlled for the dimension of the OCB that was not being examined as the dependent variable in the model.

[Table 4 about here]

\section{Results}

The results of the analysis are displayed in Table 4. Hypotheses 1a and $1 \mathrm{~b}$ predicted that there is a positive relationship between relational authenticity and OCBs (altruism and sportsmanship). For the student employee sample, relational authenticity was positively related to sportsmanship $(\beta=0.46 ; 95 \% \mathrm{CI}=[0.35,0.56] ; p<0.01)$ and not significantly related to altruism $(\beta=0.06 ; 95 \% \mathrm{CI}=[-0.01,0.13], n s)$, thus supporting Hypothesis $1 \mathrm{~b}$, but not supporting Hypothesis 1a. Secondly, Hypotheses $2 \mathrm{a}$ and $2 \mathrm{~b}$ predicted that proactive personality would enhance the relationship between relational authenticity and altruism (2a)/sportsmanship (2b). However, in the student employee sample, proactive personality had no effect on these relationships $(\beta=-0.02 ; 95 \% \mathrm{CI}=[-0.20,0.17], n s$ for altruism and $\beta=-0.11 ; 95 \% \mathrm{CI}=[-0.39$, 0.17], $n s$ for sportsmanship), thereby not supporting Hypothesis 2a or $2 b$.

\section{STUDY 2}

\section{Participants and Procedure}

The second sample consisted of $500(N=500)$ full-time employees from whom we collected self-reports of relational authenticity and OCBs. This sample is hereafter referred to as the retail employee sample. These individuals were recruited by Qualtrics using the targeted audience approach. The criteria for our sample included residence in the U.S. and full-time employment in the retail industry. We limited this sample to a single industry to control for industry effects (Baum, Locke, \& Smith, 2001). The retail industry was chosen because individuals in jobs that require product promotion tend to be less trusting (Pitesa, Goh, \& Thau, 
2018), which may manifest in lower levels of relational authenticity and, thus, a more rigorous examination of our theorization. Additionally, the retail industry is a significant part of the U.S. economy, as indicated by the aggregate retail revenue generated by the top 250 retail companies in 2012, which totaled $\$ 4.29$ trillion (Deloitte, 2014). Respondents were 30\% male, with an age range of $18-77$ and an average age of 39.06 years $(\mathrm{SD}=15.40)$, and current job tenure ranging from less than one year (19.6\%), 1-2 years (24\%), 3-4 years (18.6\%), 5-6 years $(12.6 \%), 7-8$ years $(5.6 \%), 9-10$ years $(6.2 \%), 11-15$ years $(7 \%)$, and over 16 years $(6.4 \%)$. Most $(46.2 \%)$ of the participants had a high school diploma/high school diploma equivalent with $22.2 \%$ having an associate's degree, $24.2 \%$ with a bachelor's degree, and $6 \%$ with a graduate degree.

\section{Measures}

All measures were based on a 5-point Likert scale ranging from strongly disagree (1) to strongly agree (5) with neither agree nor disagree (3) as the midpoint.

Relational Authenticity. Following Study 1, we re-tested the reliability of our adapted measure with the retail employee sample. For this sample, the Cronbach's alpha for the 7 items is 0.89 .

Organizational Citizenship Behaviors. As with Study 1, we used the 12 items from MacKenzie et al. (1993). The Cronbach's alpha is 0.88 for the 3 sportsmanship items and 0.78 for the 3 altruism items.

Proactive Personality. As with Study 1, we used 10 items from Bateman and Crant's (1993) proactive personality scale. The Cronbach's alpha for these 10 items is 0.92 .

Controls. As with Study 1, we controlled for age, gender, and current job tenure as previous research demonstrated that each may be related to dimensions of OCBs (Chiu \& Tsai, 2006; Kidder, 2002; Kuehn \& Al-Busaidi, 2002). 
[Tables 5, 6, \& 7 about here]

\section{Analyses}

As with Study 1, we first subjected all items to a confirmatory factor analysis (CFA) using IBM SPSS AMOS. The fit indices for the 4-factor structure for the retail employee sample $\left(X^{2}=456.10, d f=206, p<0.000, \mathrm{CFI}=0.96, \mathrm{GFI}=0.92, \mathrm{AGFI}=0.90, \mathrm{SRMR}=0.05\right.$, and RMSEA = 0.05) were acceptable (Hu \& Bentler, 1999). The CFA measurement model is displayed in Table 5. Means, standard deviations, and correlations among the variables are displayed in Table 6. We also assessed convergent and discriminant validities. As displayed in Table 7, all thresholds for convergent and discriminant validities are met; therefore, we contend that we have both reliability and validity in our sample.

As with Study 1, we conducted a common method variance test for this sample. We compared the unconstrained common method factor model to the fully (zero) constrained common method factor (Podsakoff et al., 2012). The test resulted in the $X^{2}$ being significantly different (difference in $X^{2}=168.4, d f=23, p<0.01$ ). Therefore, there is significant shared variance in the model, which resulted in our retaining the common latent factor for the remaining analyses. To test the hypothesized model, as with Study 1, we used the Preacher and Hayes (2004, 2008) method.

[Table 8 about here]

\section{Results}

The results for Study 2 are found in Table 8. In the retail employee sample, we found that relational authenticity was positively associated with both increased engagement in sportsmanship behaviors $(\beta=0.72 ; 95 \% \mathrm{CI}=[0.63,0.81], p<0.01)$ and altruism $(\beta=0.11 ; 95 \%$ $\mathrm{CI}=[0.04,0.17], p<0.05)$, as theorized, supporting Hypotheses 1a and 1b. Regarding the 
moderating effect of proactive personality, these hypotheses were not supported as proactive personality was not significant for both altruism $(\beta=-0.10 ; 95 \% \mathrm{CI}=[-0.21,0.02], n s)$, and sportsmanship $(\beta=0.12 ; 95 \% \mathrm{CI}=[-0.07,0.32], n s)$.

\section{POST-HOC ANALYSIS}

Corroborating previous studies (i.e., Grayson \& Shulman, 2000; Lehman, et al. 2019), age was a significant variable in most of the analyses; therefore, we decided to investigate how age differences influence OCBs, relational authenticity, and proactive personality. The student employee sample includes individuals with an average age of 24.85 while the retail employee sample involved those with an average age of 39.06. Millennials contain those born between 1981 and 1997 and Generation X refers to those born between 1965 and 1980 (Fry, 2016). Millennials are strongly represented in the student employee sample (90.3\%) and several generations, including the Silent generation (born between 1928 and 1945) and the Baby Boomers (born between 1946 and 1964) along with Generation X and Millennials, are represented in the retail employee sample. Furthermore, since generational phenomena are at the heart of organizational issues (Joshi, Dencker, Franz, \& Martocchio, 2010), we investigate how generational differences influence relational authenticity and OCBs. Age was first recoded to reflect the different generations in the retail employee sample, such that $1=$ Silent generation, 2 $=$ Baby Boomers, $3=$ Generation X, and $4=$ Millennials. This recoding resulted in 8 members of the Silent generation (1.6\%), 138 of the Baby Boomers (27.6\%), 113 of Generation X (22.6\%) and 241 of Millennials (48.2\%).

We first conducted between-participants multivariate analysis of variance (MANOVA) using the dependent variables of altruism, sportsmanship, relational authenticity, and proactive personality. Generational differences had a significant effect (Wilk's Lambda, $F(4,493)=5.84$, 
$p<0.01$ ). Subsequent univariate analysis of variance (ANOVA) tests indicated that this effect was significant for three of the four variables: sportsmanship $(F(3,496)=5.54, p<0.05$, partial $\left.\eta^{2}=0.94\right)$, relational authenticity $\left(F(3,496)=4.96, p<0.05\right.$, partial $\left.\eta^{2}=0.91\right)$, and proactive personality $\left(F(3,496)=9.90, p<0.05\right.$, partial $\left.\eta^{2}=0.99\right)$. Figure 2 displays the mean differences of the different generational types for sportsmanship, relational authenticity, and proactive personality. The results of this post-hoc suggest that generational differences do play a role in an individual's likelihood to engage in sportsmanship behaviors and levels of relational authenticity and proactive personality. Specifically, our results suggest that members of older generations have more engagement in sportsmanship behaviors and have higher levels of relational authenticity than younger generations. Likewise, members of younger generations have higher levels of proactive personality than members of older generations.

[Figure 2 about here]

\section{DISCUSSION}

Holistically, when examining the results from both studies, relational authenticity, or the feeling that an individual can be genuine (i.e., their "true self") in their relationships with coworkers and supervisors, is related to the altruism and sportsmanship dimensions of OCBs. Individuals who felt genuine in their workplace relationships engaged in more behaviors that supported the functioning of the organization, as the organization helped to fulfill a critical need (i.e., the need to belong). Both studies show that when employees feel authentic in their relationships, they are more likely to engage in sportsmanship behaviors. However, the moderating effect of proactive personality was not supported in either sample.

Our findings corroborate previous studies suggesting that proactive personality is positively related to OCBs. Specifically, the direct effect of proactive personality in both studies 
was positive and significantly related to both altruism and sportsmanship, consistent with previous literature (i.e., Li et al., 2010). Yet, when we utilized proactive personality as a moderator between relational authenticity and both altruism and sportsmanship, our findings were not significant. Because the moderating effect of proactive personality was not supported, we suggest some possible explanations for this lack of statistical significance. For instance, for the student employee sample, one possible explanation is that most of the student employees (over $57 \%$ of the 352 participants) were part-time workers. Therefore, it is possible that they did not feel that they needed to develop a sense of belonging within their company since they were only there for less than 30 hours a week. Moreover, as this sample was comprised of student employees, once these students complete their degrees, they hope to move onto a position in which they can utilize their degree, thus thinking of their current position as a temporary position (Crockford, Hordósy, \& Simms, 2015; Vinichenko, Makushkin, Melnichuk, Frolova, \& Kurbakova, 2016). Similarly, proactive personality did not influence the relationship between relational authenticity and OCBs in the retail employee sample. One possible explanation is that the generational differences may have accounted for some of this finding as well.

Interestingly, as demonstrated in our post-hoc analysis, generational differences affected levels of relational authenticity, sportsmanship, and proactive personality. The Silent Generation had the highest levels of sportsmanship, while Generation X had the lowest levels. The Silent Generation also had the highest levels of relational authenticity, with Millennials having the lowest of the four generations. The Silent Generation had the lowest levels of proactive personality, while Millennials had the highest. These generational differences suggest that there are inherent challenges that each generation faces that can influence how they relate to these various items (relational authenticity, sportsmanship, and proactive personality). 


\section{Theoretical Implications}

Our main contribution to theory is the extension of authenticity by examining its relational component through the construct of relational authenticity within the workplace. We contend that this specific exploration of one component of authenticity is an important contribution to both the authenticity literature and the field of organizational behavior as a whole. First, as noted by the Cha and colleagues (2019) review of the authenticity literature, the majority of experienced authenticity constructs have focused on predicting internal states such as wellbeing and work engagement. In contrast, externally perceived authenticity constructs (how authentic others perceive us) have primarily focused on predicting performance and image outcomes. We bridge this gap with our experienced authenticity construct of relational authenticity, which we find is related to a type of performance outcomes: OCBs. Specifically, we found that relational authenticity is related to both sportsmanship and altruism, the two OCB dimensions investigated in this research.

We also found that generational differences can account for some differences in our findings, which helps us to understand further about the complexities of the current workforce, since several generations are working in the labor force at the same time (Culpin, Millar, \& Peters, 2015; Kaifi, Nafei, Khanfar, \& Kaifi, 2012; Lewis \& Wescott, 2017). Our findings also demonstrated that different generations held different levels of relational authenticity, thereby suggesting that relational authenticity may be more important for more mature generations than for younger generations. This finding corroborates other researchers that suggests that individuals become truer to themselves and their beliefs as they mature (e.g., Grayson \& Shulman, 2000; Johnson, Brekke, Strommen, \& Underwager, 1974; Lehman et al., 2019; Shamir 
\& Eilam, 2005). In other words, our post-hoc analyses suggest that age is an important factor to consider when examining whether authenticity will influence organizational outcomes.

Drawing from belongingness theory, we also contribute to theory by demonstrating how relational authenticity can help employees feel like they belong within their group of coworkers. That is, when certain employees feel like they can be their true selves at work with their coworkers, then they feel the need to belong within that group and engage in more discretionary behaviors. Consequently, our findings suggest that workplace relationships matter for individuals and that the quality of these relationships can have an impact on the amount of discretionary behaviors that an individual engages in. Yet, relational authenticity might not matter to some employees, such as those who are younger, or those who view their job as temporary. Moreover, as demonstrated across both of our studies, an individual's proactive personality does not appear to influence how an individual feels they belong within their group of coworkers. That is, an individual feeling true to themselves supersedes an actionable personality trait, in that when they feel like they are themselves at work, they feel a higher sense of belonging within their realm of coworkers, i.e., "they found their place."

\section{Practical Implications}

Our primary implication for practice is that our research adds to the burgeoning research on authenticity by showing, through two separate demographic samples, that authenticity has benefits for organizations in addition to direct benefits to individuals (as evidenced by prior research on authenticity and well-being; cf. Cha et al., 2019). While holistically we did find a positive relationship between relational authenticity and both sportsmanship behaviors and altruistic behaviors, we did note an interesting discrepancy between our two samples. Specifically, while we found increased engagement in both discretionary behaviors for our retail 
employee sample, in our much younger student employee sample we only noted an increase in sportsmanship behaviors (not altruistic behaviors). Thus, relational authenticity appears to be less beneficial for younger employees (such as Millennials) if discretionary behaviors like altruism are a desired outcome. With older employees, conversely, relational authenticity appears to have a positive influence on engagement in extra-role behaviors like altruism and sportsmanship. This does not mean, however, that relational authenticity is a bad thing for younger employees - relational authenticity did lead to an increase in sportsmanship behaviors. For now, this research indicates to practitioners that relational authenticity, while important, may have different effects depending on the age of the employee and is thus no panacea. However, overall across both samples, we found that relational authenticity inspired employees to engage in OCBs, as they were buoyed into discretionary behaviors through the satisficing of the important need of belongingness. Consequently, if organizations want employees to engage in more discretionary behaviors, they should focus on fostering workplace environments that promote and support true, authentic expression.

\section{Limitations and Future Directions}

While our adapted relational authenticity scale is a step in the right direction to understanding and measuring authenticity, more refining of the scale and construct of relational authenticity is necessary. More work on relational authenticity and how it relates to other organizational outcomes is also needed, as is research on why specifically relational authenticity encourages discretionary behaviors in older generations, which may be due to feeling like they belong to their work group, while younger generations may not have this feeling. A greater understanding of how relational authenticity manifests itself in the workplace is also warranted. 
Methodologically, there are three primary limitations: the self-report nature of the data, potential issues with common method variance due to the cross-sectional nature of the data, and the nature of our sample. The critiques of self-report data are justified (e.g., Brannick, Michaels, \& Baker, 1989; Brief, Burke, George, Robinson, \& Webster, 1988), as they are often used too frequently and without regard to the research questions being examined (Spector, 1994). The criticism, however, has to do with self-report data and their use in measuring the objective job environment. Self-report data is generally considered acceptable when measuring an individual's feelings about and perceptions of work (Conway \& Lance, 2010; Spector, 1994), which is how relational authenticity should be classified. Moreover, relational authenticity can be measured no other way than through self-report data, since only the individual can assess if they are their true self with others. Regarding self-report data and OCBs, there is evidence that citizenship behaviors tend to be over-inflated possibly due to social desirability. On the other end of the spectrum, however, other methods of measuring OCBs are also imperfect, as coworker reports tend to underestimate relationships (Donaldson \& Grant-Vallone, 2002). Therefore, while our self-reported data has inherent limitations, we argue that it is an appropriate methodology given our variables of interest.

Our second limitation is the use of cross-sectional data and the resulting concern of common method variance (CMV). While common method variance is a serious concern in organizational behavior research (e.g., Cote \& Buckley, 1987), recent research has argued that the effects of CMV are inflated, as a study of research on the theory of planned behavior indicated that CMV did not alter the substantive inferences of study results (Schaller, Patil, \& Malhotra, 2015). Moreover, we followed the recommended techniques for controlling for CMV by Podsakoff, Mackenzie, Lee, and Podsakoff (2003), including protecting respondent 
anonymity and improving scale items, as well as accounting for CMV within our hypothesis testing following recommendations by Podsakoff et al. (2012). Regardless of our attempts to address these two limitations, these two methodological limitations do limit the generalizability of our findings.

Our third methodological limitation has to do with the student employee sample, where we used a convenience sample and surveyed college students, although they all were employed and able to answer questions about their work environment. It is also important to note a critique of how our Study 2 data was collected, which was through panel data. A critique of online sampling strategies (i.e., Qualtrics) argues that online panels may not perfectly mirror organizational samples due to some individuals being unemployed (Roulin, 2015). While there has been doubt about the validity of panel data, recent research has found that panel data results are similar to the general adult population, with good reliability and no issues with normality (Roulin, 2015). These results support claims about the quality of online panel data (Brandon, Long, Loraas, Mueller-Phillips, \& Vasant, 2013). For these reasons, we argue that our use of panel data is acceptable given our population of interest and the relationships under investigation. Future research should employ an organization-based sample in order to gain insight into the relational authenticity characteristics of a single organization.

Aside from these limitations, there are some exciting avenues for future research that have arisen out of this research. First, there is a plethora of research linking various forms of authenticity to outcomes, yet more research is needed on the antecedents of authenticity and, in relation to our work, more is needed on what drives or inspires relational authenticity in the workplace. Next, while we controlled for the effects of industry through the emphasis of the retail context, future research should employ an organization-based sample in order to gain 
insight into the relational authenticity characteristics of a single organization. Additionally, while our research indicated the importance of relational authenticity affecting both altruism and sportsmanship, more research is needed to understand the effects of relational authenticity on the different types of citizenship behaviors. Altruism is viewed as a manifestation of OCB-Is, or individually-directed OCBs, while sportsmanship is a manifestation of OCB-O, or organizationally-directed OCBs (Hoffman, Blair, Meriac, \& Woehr, 2007). Future researchers could explore another OCB-I variable, such as courtesy, or other OCB-O variables, such as civic virtue and conscientiousness. Despite proactive personality not playing a part in our two studies, future researchers could evaluate other personality traits, such as the Big Five, core selfevaluations, and the Dark Triad. Additionally, based on our post-hoc analysis, age matters and, thus, investigating the reasons why different generations have higher or lower levels of relational authenticity is also worth exploring.

While we found a significant and positive relationship between experienced relational authenticity in the workplace and that same individual engaging in discretionary behaviors, relational authenticity may have a negative relationship with more objective measures of performance or team-level emergent states, such as team cohesion. This is because when some people are authentic, they exhibit negative traits, like apathy or narcissism, that most likely would have a negative relationship with other types of outcomes. Thus, people being relationally authentic in the workplace could, in fact, be detrimental to team dynamics and performance if enough individuals exhibited undesirable traits. While these individuals may engage in more individual discretionary behaviors (which are desirable), these effects might be seen only at the individual level for some teams or units. Additionally, there may be other instances where relational authenticity could be detrimental to the workplace. For example, for those who work 
primarily in emergency situations (i.e., EMTs, firefighters, emergency room workers, etc.), coworkers may not be concerned about how true to themselves they are being when an individual's life is hanging in the balance; rather, they are primarily concerned with getting the needed information to save that individual's life. If they focused on being authentic in their relationships with their coworkers at that time, then they could potentially jeopardize that individual's life. Yet, when these emergency workers are not facing an emergency, then relational authenticity may be of upmost importance in strengthening the bond among coworkers. This is a question for future researchers to answer. Accordingly, more research is needed to assess the effects of relational authenticity on units and teams, to understand when relational authenticity is necessary, and to examine the traits exhibited by the team members. Lastly, future researchers should explore the effects of organizational culture and structure, as well as position type, on relational authenticity.

\section{CONCLUSION}

To summarize, we hypothesized that relational authenticity would be positively related to OCBs and that this relationship would be moderated by proactive personality. Holistically, across our two studies, this model was supported by the results of our study of retail employees, but not with our student employees. We extend the literature by adapting a scale to measure relational authenticity in the workplace, elucidating which types of OCBs relational authenticity predicts and empirically finding a relationship between relational authenticity and the OCB dimensions of sportsmanship and altruism. Future research should be conducted to further delineate the construct of authenticity to better understand its relationship with other variables, such as task performance. 


\section{REFERENCES}

Asgari, A., Silong, A. D., Ahmad, A., \& Samah, B. A. (2008). The relationship between transformational leadership behaviors, organizational justice, leader-member exchange, perceived organizational support, trust in management and organizational citizenship behaviors. European Journal of Scientific Research, 23(2), 227-242.

Babcock-Roberson, M. E., \& Strickland, O. J. (2010). The relationship between charismatic leadership, work engagement, and organizational citizenship behaviors. The Journal of Psychology, 144(3), 313-326.

Ball, G. A., Trevino, L. K., \& Sims, H. P. (1994). Just and unjust punishment: Influences on subordinate performance and citizenship. Academy of Management Journal, 37(2), 299322.

Bandura, A. (1986). The explanatory and predictive scope of self-efficacy theory. Journal of Social and Clinical Psychology, 4(3), 359-373.

Bateman, T. S., \& Crant, J. M. (1993). The proactive component of organizational behavior: A measure and correlates. Journal of Organizational Behavior, 14(2), 103-118.

Bateman, T. S., \& Organ, D. W. (1983). Job satisfaction and the good soldier: The relationship between affect and employee "citizenship." Academy of Management Journal, 26(4), 587-595.

Baum, J. R., Locke, E. A., \& Smith, K. G. (2001). A multidimensional model of venture growth. Academy of Management Journal, 44(2), 292-303.

Baumeister, R. F., \& Leary, M. R. (1995). The need to belong: desire for interpersonal attachments as a fundamental human motivation. Psychological Bulletin, 117(3), 497529.

Baumeister, R. F., \& Twenge, J. M. (2003). The social self. In T. Millon \& M. J. Lerner (Eds.), Handbook of psychology: Personality and social psychology (Vol. 5, pp. 327-352). New York: John Wiley

Bettencourt, L. A., Gwinner, K. P., \& Meuter, M. L. (2001). A comparison of attitude, personality, and knowledge predictors of service-oriented organizational citizenship behaviors. Journal of Applied Psychology, 86(1), 29-41.

Bolino, M. C., \& Turnley, W. H. (1999). Measuring impression management in organizations: A scale development based on the Jones and Pittman taxonomy. Organizational Research Methods, 2(2), 187-206.

Bowler, W. M., \& Brass, D. J. (2006). Relational correlates of interpersonal citizenship behavior: a social network perspective. Journal of Applied Psychology, 91(1), 70-82.

Brandon, D. M., Long, J. H., Loraas, T. M., Mueller-Phillips, J., \& Vansant, B. (2013). Online instrument delivery and participant recruitment services: Emerging opportunities for behavioral accounting research. Behavioral Research in Accounting, 26(1), 1-23.

Brannick, M. T., Michaels, C. E., \& Baker, D. P. (1989). Construct validity of in-basket scores. Journal of Applied Psychology, 74(6), 957-963. 
Brief, A. P., Burke, M. J., George, J. M., Robinson, B. S., \& Webster, J. (1988). Should negative affectivity remain an unmeasured variable in the study of job stress? Journal of Applied Psychology, 73(2), 193-198.

Brotheridge, C. M., \& Grandey, A. A. (2002). Emotional labor and burnout: Comparing two perspectives of "people work". Journal of Vocational Behavior, 60(1), 17-39.

Brown, D. J., Cober, R. T., Kane, K., Levy, P. E., \& Shalhoop, J. (2006). Proactive personality and the successful job search: A field investigation with college graduates. Journal of Applied Psychology, 91(3), 717-726.

Buss, D. M. (1987). Selection, evocation, and manipulation. Journal of Personality and Social Psychology, 53(6), 1214-1221.

Cable, D. M., \& Kay, V. S. (2012). Striving for self-verification during organizational entry. Academy of Management Journal, 55(2), 360-380.

Cable, D. M., Gino, F., \& Staats, B. R. (2013). Breaking them in or eliciting their best? Reframing socialization around newcomers' authentic self-expression. Administrative Science Quarterly, 58(1), 1-36.

Caporael, L. R., \& Brewer, M. B. (1995). Hierarchical evolutionary theory: There is an alternative, and it's not creationism. Psychological Inquiry, 6(1), 31-34.

Carroll, G. R. (2015). Authenticity: Attribution, value and meaning. In R. A. Scott, S. M. Kosslyn, \& N. Pinkerton (Eds.), Emerging trends in the social and behavioral sciences (pp. 1-13). Wiley Online Library.

Carroll, S. J., Hill, E. J., Yorgason, J. B., Larson, J. H., \& Sandberg, J. G. (2013). Couple communication as a mediator between work-family conflict and marital satisfaction. Contemporary Family Therapy, 35, 530-545.

Caza, B. B., Moss, S., \& Vough, H. (2017). From synchronizing to harmonizing: The process of authenticating multiple work identities. Administrative Science Quarterly, 63(4), 703745 .

Cha, S. E., Hewlin, P. F., Roberts, L. M., Buckman, B. R., Leroy, H., Steckler, E. L., Ostermeier, K. \& Cooper, D. (2019). Being Your True Self at Work: Integrating the Fragmented Research on Authenticity in Organizations. Academy of Management Annals, 13(2), 633671.

Chiu, S. F., \& Tsai, M. C. (2006). Relationships among burnout, job involvement, and organizational citizenship behavior. The Journal of Psychology, 140(6), 517-530.

Conley, J. J. (1985). Longitudinal stability of personality traits: A multitrait-multimethodmultioccasion analysis. Journal of Personality and Social Psychology, 49(5), 1266-1282.

Conway, J. M., \& Lance, C. E. (2010). What reviewers should expect from authors regarding common method bias in organizational research. Journal of Business and Psychology, 25, 325-334.

Cote, J. A., \& Buckley, M. R. (1987). Estimating trait, method, and error variance: Generalizing across 70 construct validation studies. Journal of Marketing Research, 315-318. 
Crant, J. M. (1996). The proactive personality scale as a predictor of entrepreneurial intentions. Journal of Small Business Management, 34, 42-49.

Crant, J. M., \& Bateman, T. S. (2000). Charismatic leadership viewed from above: The impact of proactive personality. Journal of Organizational Behavior, 21(1), 63-75.

Crockford, J., Hordósy, R., \& Simms, K. S. (2015). 'I really need a job, like, for money and stuff': Student finance, part-time work and the student experience at a northern red-brick university. Widening Participating and Lifelong Learning, 17(3), 89-109.

Culpin, V., Millar, C., \& Peters, K. (2015). Multi-generational frames of reference: Managerial challenges of four social generations in the organization. Journal of Managerial Psychology, 30(1).

Deloitte Consulting L.L.P., \& Bersin (2014). Global human capital trends 2014. Engaging the $21^{\text {st }}$-century workforce. Retrieved from http://www.deloitte.com/assets/DcomNamibia/GlobalHumanCapitalTrends2014_030714.pdf.

Deluga, R. J. (1994). Supervisor trust building, leader-member exchange and organizational citizenship behavior. Journal of Occupational and Organizational Psychology, 67, 315326. http://dx.doi.org/10.1111/j.2044-8325.1994.tb00570.x

Donaldson, S. I., \& Grant-Vallone, E. J. (2002). Understanding self-report bias in organizational behavior research. Journal of Business and Psychology, 17(2), 245-260. http://dx.doi.org/10.1023/A:1019637632584

Emmerich, A. I., \& Rigotti, T. (2017). Reciprocal relations between work-related authenticity and intrinsic motivation, work ability and depressivity: A two-wave study. Frontiers in Psychology, 8, 1-12.

Frone, M. R., Russell, M., \& Cooper, M. L. (1992). Antecedents and outcomes of work-family conflict: Testing a model of the work-family interface. Journal of Applied Psychology, 77(1), 65-78.

Fry, R. (2016). Millennials overtake Baby Boomers as America’s largest generation. Pew Research Center, 25.

Fuller Jr, B., \& Marler, L. E. (2009). Change driven by nature: A meta-analytic review of the proactive personality literature. Journal of Vocational Behavior, 75(3), 329-345.

Gardner, W. L., Cogliser, C. C., Davis, K. M., \& Dickens, M. P. (2011). Authentic leadership: A review of the literature and research agenda. The Leadership Quarterly, 22(6), 11201145.

Goldberg, L. S., \& Grandey, A. A. (2007). Display rules versus display autonomy: emotion regulation, emotional exhaustion, and task performance in a call center simulation. Journal of Occupational Health Psychology, 12(3), 301-318.

Goldman, B. M., \& Kernis, M. H. (2001). Development of the authenticity inventory. Unpublished data, University of Georgia.

Grandey, A. A., Fisk, G. M., Mattila, A. S., Jansen, K. J., \& Sideman, L. A. (2005). Is "service with a smile" enough? Authenticity of positive displays during service encounters. Organizational Behavior and Human Decision Processes, 96(1), 38-55. 
Grayson, K., \& Shulman, D. (2000). Indexicality and the verification function of irreplaceable possessions: A semiotic analysis. Journal of Consumer Research, 27(1), 17-30.

Guzman, F. A., \& Espejo, A. (2015). Dispositional and situational differences in motives to engage in citizenship behavior. Journal of Business Research, 68(2), 208-215.

Hair, J., Black, W., Babin, B., \& Anderson, R. (2010). Multivariate data analysis (7 $7^{\text {th }}$ ed.). Upper Saddle River, NJ: Prentice-Hall, Inc.

Hancock, G. R. (2001). Rethinking construct reliability within latent variable systems. Structural Equation Modeling: Present and Future, 195-216.

Harter, S. (2002). Authenticity. In C. R. Snyder \& S. Lopez (Eds.), Handbook of positive psychology, 382-394. London: Oxford University Press.

Hayes, A. F. (2009). Beyond Baron and Kenny: Statistical mediation analysis in the new millennium. Communication Monographs, 76, 408-420.

Hayes, A. F. (2018). Partial, conditional, and moderated mediation: Quantification, inference, and interpretation. Communication Monographs, 85(1), 4-40.

Hewlin, P. F. (2009). Wearing the cloak: antecedents and consequences of creating facades of conformity. Journal of Applied Psychology, 94(3), 727-741.

Hewlin, P. F., Dumas, T. L., \& Burnett, M. F. (2017). To thine own self be true? Facades of conformity, values incongruence, and the moderating impact of leader integrity. Academy of Management Journal, 60(1), 178-199.

Hewlin, P. F., Kim, S. S., \& Song, Y. H. (2016). Creating facades of conformity in the face of job insecurity: A study of consequences and conditions. Journal of Occupational and Organizational Psychology, 89(3), 539-567.

Hoffman, B. J., Blair, C. A., Meriac, J. P., \& Woehr, D. J. (2007). Expanding the criterion domain? A quantitative review of the OCB literature. Journal of Applied Psychology, 92(2), 555-566.

Hu, L. T., \& Bentler, P. M. (1999). Cutoff criteria for fit indices in covariance structure analysis: Conventional criteria versus new alternatives. Structural Equation Modeling: A Multidisciplinary Journal, 6(1), 1-55.

Johnson, A. L., Brekke, M. L., Strommen, M. P., \& Underwager, R. C. (1974). Age differences and dimensions of religious behavior. Journal of Social Issues, 30(3), 43-67.

Joshi, A., Dencker, J. C., Franz, G., \& Martocchio, J. J. (2010). Unpacking generational identities in organizations. Academy of Management Review, 35(3), 392-414.

Kaifi, B. A., Nafei, W. A., Khanfar, N. M., \& Kaifi, M. M. (2012). A multi-generational workforce: Managing and understanding Millennials. International Journal of Business and Management, 7(4), 88-93.

Kernis, M. H. (2003). Toward a conceptualization of optimal self-esteem. Psychological Inquiry, $14(1), 1-26$.

Kernis, M. H., \& Goldman, B. M. (2006). A multicomponent conceptualization of authenticity: Theory and research. Advances in Experimental Social Psychology, 38, 283-357. 
Kidder, D. L. (2002). The influence of gender on the performance of organizational citizenship behaviors. Journal of Management, 28, 629-648.

Knoll, M., \& van Dick, R. (2013). Authenticity, employee silence, prohibitive voice, and the moderating effect of organizational identification. The Journal of Positive Psychology, $8(4), 346-360$.

Kolden, G. G., Klein, M. H., Wang, C. C., \& Austin, S. B. (2011). Congruence/genuineness. Psychotherapy, 48(1), 65.

Kuehn, K. W., \& Al-Busaidi, Y. (2002). Citizenship behavior in a non-Western context: An examination of the role of satisfaction, commitment and job characteristics on selfreported OCB. International Journal of Commerce \& Management, 12, 107-125.

Lehman, D. W., O’Connor, K., Kovacs, B., \& Newman, G. E. (2019). Authenticity. Academy of Management Annals, 13(1), 1-42.

Leroy, H., Anseel, F., Dimitrova, N. G., \& Sels, L. (2013). Mindfulness, authentic functioning, and work engagement: A growth modeling approach. Journal of Vocational Behavior, 82(3), 238-247.

Lewis, L. F., \& Wescott, H. D. (2017). Multi-generational workforce: Four generations united in lean. Journal of Business Studies Quarterly, 8(3), 1-14.

Li, N., Liang, J., \& Crant, J. M. (2010). The role of proactive personality in job satisfaction and organizational citizenship behavior: A relational perspective. Journal of Applied Psychology, 95(2), 395.

Liedtka, J. (2008). Strategy making and the search for authenticity. Journal of Business Ethics, 80(2), 237-248.

Lopez, F. G., \& Rice, K. G. (2006). Preliminary development and validation of a measure of relationship authenticity. Journal of Counseling Psychology, 53(3), 362-371.

Lykken, D. T. (1968). Statistical significance in psychological research. Psychological Bulletin, 70(3), 151-159.

MacKenzie, S. B., Podsakoff, P. M., \& Fetter, R. (1993). The impact of organizational citizenship behavior on evaluations of salesperson performance. Journal of Marketing, 57(1), 70-80.

Magnusson, D., \& Endler, N. S. (1977). Personality at the crossroads: Current issues in interactional psychology. Lawrence Erlbaum Associates; New York: Halsted Press Division of Wiley.

Malhotra, N. K., \& Dash, S. (2011). Marketing research: An applied orientation. London.

McCrae, R. R., \& Costa Jr., P. T. (1994). The stability of personality: Observations and evaluations. Current Directions in Psychological Science, 3(6), 173-175.

Myers, D. G. (1992). The pursuit of happiness: What makes a person happy-and why. William Morrow \& Company.

Novicevic, M. M., Harvey, M. G., Ronald, M., \& Brown-Radford, J. A. (2006). Authentic leadership: A historical perspective. Journal of Leadership \& Organizational Studies, 13(1), 64-76. 
Organ, D. W. (1988). Organizational citizenship behavior: The good soldier syndrome. Lexington, MA: Lexington Books.

Pitesa, M., Goh, Z., \& Thau, S. (2018). Mandates of dishonesty: The psychological and social costs of mandated attitude expression. Organization Science, 29(3), 418-431.

Podsakoff, P. M., \& MacKenzie, S. B. (1997). The impact of organizational citizenship behavior on organizational performance: A review and suggestions for future research. Human Performance, 10, 133-151.

Podsakoff, P. M., MacKenzie, S. B., \& Podsakoff, N. P. (2012). Sources of method bias in social science research and recommendations on how to control it. Annual Review of Psychology, 63, 539-569.

Podsakoff, P. M., MacKenzie, S. B., Lee, J. Y., \& Podsakoff, N. P. (2003). Common method biases in behavioral research: a critical review of the literature and recommended remedies. Journal of Applied Psychology, 88(5), 879-903.

Preacher, K. J., \& Hayes, A. F. (2004). SPSS and SAS procedures for estimating indirect effects in simple mediation models. Behavior Research Methods, 36, 717-731.

Preacher, K. J., \& Hayes, A. F. (2008). Asymptotic and resampling strategies for assessing and comparing indirect effects in multiple mediator models. Behavior Research Methods, 40, 879-891.

Roberts, L. M., Cha, S. E., Hewlin, P. F., \& Settles, I. H. (2009). Bringing the inside out: Enhancing authenticity and positive identity in organizations. In L. M. Roberts \& J. E. Dutton (Eds.), Exploring positive identities and organizations: Building a theoretical and research foundation (pp. 149-169). New York: Taylor \& Francis Group, LLC.

Rotundo, M., \& Sackett, P. R. (2002). The relative importance of task, citizenship, and counterproductive performance to global ratings of job performance: A policy-capturing approach. Journal of Applied Psychology, 87, 66-80.

Roulin, N. (2015). Don't throw the baby out with the bathwater: Comparing data quality of crowdsourcing, online panels, and student samples. Industrial and Organizational Psychology, 8(2), 190-196.

Rubin, R. S., Bommer, W. H., \& Bachrach, D. G. (2010). Operant leadership and employee citizenship: A question of trust? The Leadership Quarterly, 21(3), 400-408.

Schaller, T. K., Patil, A., \& Malhotra, N. K. (2015). Alternative techniques for assessing common method variance: An analysis of the theory of planned behavior research. Organizational Research Methods, 18(2), 177-206.

Seibert, S. E., Kraimer, M. L., \& Liden, R. C. (2001). A social capital theory of career success. Academy of Management Journal, 44(2), 219-237.

Shamir, B., \& Eilam, G. (2005). "What's your story?” A life-stories approach to authentic leadership development. The Leadership Quarterly, 16(3), 395-417.

Sheldon, K. M., \& Kasser, T. (1995). Coherence and congruence: two aspects of personality integration. Journal of Personality and Social Psychology, 68(3), 531-543. 
Sheldon, K. M., Ryan, R. M., Rawsthorne, L. A. I. R. D., \& Ilardi, B. (1997). Trait self and true self: Cross-role variation in the Big Five traits and its relations with authenticity and subjective well-being. Journal of Personality and Social Psychology, 73(6), 1380-1393.

Snyder, M., \& Gangestad, S. (1986). On the nature of self-monitoring: matters of assessment, matters of validity. Journal of Personality and Social Psychology, 51(1), 125-139.

Spector, P. E. (1994). Using self-report questionnaires in OB research: A comment on the use of a controversial method. Journal of Organizational Behavior, 15(5), 385-392.

Stevens, L. E., \& Fiske, S. T. (1995). Motivation and cognition in social life: A social survival perspective. Social cognition, 13(3), 189-214.

Strube, M. J. (1988). The decision to leave an abusive relationship: empirical evidence and theoretical issues. Psychological bulletin, 104(2), 236.

Tatman, A. W., Hovestadt, A. J., Yelsma, P., Fenell, D. L., \& Canfield, B. S. (2006). Work and family conflict: An often overlooked issue in couple and family therapy. Contemporary Family Therapy, 28(1), 39-51.

Thompson, J. A. (2005). Proactive personality and job performance: A social capital perspective. Journal of Applied Psychology, 90(5), 1011-1017.

Trougakos, J. P., Beal, D. J., Cheng, B. H., Hideg, I., \& Zweig, D. (2015). Too drained to help: A resource depletion perspective on daily interpersonal citizenship behaviors. Journal of Applied Psychology, 100(1), 227-236.

Valsania, S. E., León, J. A. M., Alonso, F. M., \& Cantisano, G. T. (2012). Authentic leadership and its effect on employees' organizational citizenship behaviours. Psicothema, 24(4), 561-566.

van den Bosch, R. \& Taris, T. W. (2014). Authenticity at work: Development and validation of an individual authenticity measure at work. Journal of Happiness Studies, 15(1), 1-18.

Vinichenko, M. V., Makushkin, S. A., Melnichuk, A. V., Frolova, E. V., \& Kurbakova, S. N. (2016). Student employment during college studies and after career start. International Review of Management and Marketing, 6(5S), 23-29.

Wat, D., \& Shaffer, M. A. (2005). Equity and relationship quality influences on organizational citizenship behaviors: The mediating role of trust in the supervisor and empowerment. Personnel Review, 34(4), 406-422.

Wegner, D. M., Erber, R., \& Raymond, P. (1991). Transactive memory in close relationships. Journal of Personality and Social Psychology, 61(6), 923-929.

Wong, C. A., Laschinger, H. K. S., \& Cummings, G. G. (2010). Authentic leadership and nurses' voice behaviour and perceptions of care quality. Journal of Nursing Management, 18(8), 889-900.

Wood, A. M., Linley, P. A., Maltby, J., Baliousis, M., \& Joseph, S. (2008). The authentic personality: A theoretical and empirical conceptualization and the development of the Authenticity Scale. Journal of Counseling Psychology, 55(3), 385-399. 


\section{Table 1}

CFA Measurement Model: AMOS Estimates for Student Employee Sample (Study 1)

Std. $\lambda$

Estimate

\section{Relational Authenticity}

1. Sometimes I find myself trying to impress my supervisor into believing something about me that isn't really true.*

$\begin{array}{lr}0.61 & \lambda \text { set to } 1 \\ 0.60 & 9.56 \\ 0.63 & 8.84 \\ 0.58 & 8.40 \\ 0.75 & 8.97 \\ 0.68 & 9.31 \\ 0.67 & 9.13\end{array}$

3. I purposefully hide my true feelings about some things in order to avoid upsetting my supervisor.*

4. I'm willing to tell a "white lie" about myself to keep my supervisor happy.*

5. There are times I find myself calculating the risks of expressing my true feelings to my supervisor.*

6. Sometimes I feel like I am two different people - one when I'm at work and one when I'm by myself.*

7. I hesitate saying things to my supervisor when s/he may not want to hear them.*

T-Stats

\section{Proactive Personality}

1. I am constantly on the lookout for new ways to improve my life.

2. Wherever I have been, I have been a powerful force for constructive change.

$0.60 \lambda$ set to 1

3. Nothing is more exciting than seeing my ideas turn into reality.

0.66

9.74

4. If I see something I don't like, I fix it.

0.62

10.44

$0.62 \quad 9.40$

5. No matter what the odds, if I believe in something, I will make it happen.

$0.66 \quad 9.74$

6. I love being a champion for my ideas, even against others' opposition.

$0.60 \quad 9.05$

7. I excel at identifying opportunities.

$0.79 \quad 11.04$

8. I am always looking for better ways to do things.

0.70

10.19

9. If I believe in an idea, no obstacle will prevent me from making it happen.

0.63

9.36

10. I can spot a good opportunity long before others can.

0.65

9.63

$\underline{O C B}-$ Altruism

1. I help orient new employees even though it is not required.

$\begin{array}{lc}0.48 & \lambda \text { set to } 1 \\ 0.91 & 7.30 \\ 0.67 & 7.94\end{array}$

2. I am always ready to help or to lend a helping hand to those around me.

\section{$\underline{O C B}$ - Sportsmanship}

1. I consume a lot of time complaining about trivial matters.*

2. I tend to make "mountains out of molehills" (makes problems bigger than they are).*

3. I always focus on what's wrong my situation, rather than the positive side of it.*

$0.69 \quad 11.62$

Global fit indices: $X^{2}=346.33, d f=215, p<0.001$; CFI $=0.96$, GFI $=0.92$, AGFI $=0.90$, SRMR $=0.05$, RMSEA $=0.04$

* reverse-coded items 
Table 2

Means, Descriptive Statistics, and Correlations for Student Employee Sample (Study 1)

\begin{tabular}{lcccccccc}
\hline Variable & $\mathrm{M}$ & $\mathrm{SD}$ & 1 & 2 & 3 & 4 & 5 & 6 \\
\hline 1. Relational Authenticity & 3.50 & 0.79 & $(0.83)$ & & & & & \\
2. OCB-Sportsmanship & 3.86 & 0.91 & $0.33^{* *}$ & $(0.80)$ & & & & \\
3. OCB-Altruism & 4.21 & 0.59 & $0.12^{*}$ & 0.09 & $(0.69)$ & & & \\
4. Proactive Personality & 4.10 & 0.54 & $0.19^{* *}$ & 0.10 & $0.27^{* *}$ & $(0.89)$ & & \\
5. Age & 24.85 & 6.80 & $0.14^{*}$ & $0.22^{* *}$ & 0.08 & -0.06 & - & \\
6. Gender & 1.58 & 0.50 & -0.01 & -0.03 & 0.06 & -0.03 & -0.05 & - \\
7. Tenure & 1.94 & 0.99 & 0.07 & 0.02 & 0.02 & -0.03 & $0.54^{* *}$ & $-0.14^{* *}$ \\
\hline
\end{tabular}

$* \mathrm{p}<0.05$, two-tailed. $* * \mathrm{p}<0.01$, two-tailed. $\mathrm{N}=352$. 
Table 3

Convergent and Discriminant Validities for Student Employee Sample (Study 1)

\begin{tabular}{lcccccccc}
\hline & CR & AVE & MSV & MaxR $(\mathrm{H})$ & $\begin{array}{c}\text { Proactive } \\
\text { Personality }\end{array}$ & $\begin{array}{c}\text { Relational } \\
\text { Authenticity }\end{array}$ & Sportsmanship & Altruism \\
\hline Proactive Personality & 0.88 & 0.43 & 0.12 & 0.89 & 0.66 & & & \\
Relational Authenticity & 0.83 & 0.42 & 0.15 & 0.84 & 0.22 & 0.65 & 0.77 & 0.18 \\
Sportsmanship & 0.81 & 0.59 & 0.15 & 0.83 & 0.11 & 0.89 & 0.15 & 0.11 \\
Altruism & 0.74 & 0.50 & 0.12 & 0.86 & 0.35 & 0.15 & \\
\hline
\end{tabular}

Note: The numbers in diagonal cells are $\sqrt{ } \mathrm{AVE} ; \mathrm{CR}=$ composite reliability, $\mathrm{AVE}=$ average variance extracted, $\mathrm{MSV}=$ maximum shared variance, $\operatorname{Max} R(H)=$ maximum reliability. 
Table 4

Preacher and Hayes PROCESS Results for Student Employee Sample (Study 1)

\begin{tabular}{|c|c|c|c|c|}
\hline & \multicolumn{4}{|c|}{ Dependent variable: Altruism } \\
\hline & $B$ & SE & LLCI & ULCI \\
\hline \multicolumn{5}{|l|}{ Controls } \\
\hline Age & $0.01^{+}$ & 0.01 & -0.01 & 0.01 \\
\hline Gender & 0.05 & 0.04 & -0.03 & 0.12 \\
\hline Current Job Tenure & -0.02 & 0.02 & -0.06 & 0.02 \\
\hline \multicolumn{5}{|l|}{ Main Effects } \\
\hline Relational Authenticity $(a)$ & $0.06^{+}$ & 0.04 & -0.01 & 0.13 \\
\hline Proactive Personality $(b)$ & $0.50 * *$ & 0.05 & 0.40 & 0.61 \\
\hline \multicolumn{5}{|l|}{ Two-way Interaction } \\
\hline$a \times b$ & -0.02 & 0.09 & -0.20 & 0.17 \\
\hline$R$ & $0.48 * *$ & & & \\
\hline$R^{2}$ & $0.23 * *$ & & & \\
\hline
\end{tabular}

\begin{tabular}{|c|c|c|c|c|}
\hline & \multicolumn{4}{|c|}{ Dependent variable: Sportsmanship } \\
\hline & $B$ & SE & LLCI & ULCI \\
\hline \multicolumn{5}{|l|}{ Controls } \\
\hline Age & $0.02 * *$ & 0.01 & 0.01 & 0.03 \\
\hline Gender & -0.08 & 0.06 & -0.19 & 0.03 \\
\hline Current Job Tenure & $-0.08 *$ & 0.03 & -0.15 & -0.02 \\
\hline \multicolumn{5}{|l|}{ Main Effects } \\
\hline Relational Authenticity $(a)$ & $0.46^{* *}$ & 0.05 & 0.35 & 0.56 \\
\hline Proactive Personality $(b)$ & $0.20 *$ & 0.09 & 0.02 & 0.38 \\
\hline \multicolumn{5}{|l|}{ Two-way Interaction } \\
\hline$a \times b$ & -0.11 & 0.14 & -0.39 & 0.17 \\
\hline$R$ & $0.51 * *$ & & & \\
\hline$R^{2}$ & $0.26 * *$ & & & \\
\hline
\end{tabular}




\section{Table 5}

CFA Measurement Model: AMOS Estimates for Retail Employee Sample (Study 2)

Std. $\lambda$

Estimate

T-Stats

Relational Authenticity

1. Sometimes I find myself trying to impress my supervisor into believing something about me that isn't really true.*

$0.65 \lambda$ set to 1

2. If my supervisor knew the real me, s/he would probably be surprised and disappointed.

0.71

14.95

3. I purposefully hide my true feelings about some things in order to avoid upsetting my supervisor.*

$0.75 \quad 13.68$

4. I'm willing to tell a "white lie" about myself to keep my supervisor happy.*

$0.70 \quad 14.83$

5. There are times I find myself calculating the risks of expressing my true feelings to my supervisor.*

$0.77 \quad 13.76$

6. Sometimes I feel like I am two different people - one when I'm at work and one when I'm by myself.*

$0.72 \quad 13.31$

7. I hesitate saying things to my supervisor when s/he may not want to hear them.*

\section{Proactive Personality}

1. I am constantly on the lookout for new ways to improve my life.

2. Wherever I have been, I have been a powerful force for constructive change.

3. Nothing is more exciting than seeing my ideas turn into reality.

0.75

13.15

4. If I see something I don't like, I fix it.

5. No matter what the odds, if I believe in something, I will make it happen.

$0.80 \quad 13.46$

6. I love being a champion for my ideas, even against others' opposition.

$0.74 \quad 13.14$

7. I excel at identifying opportunities.

$0.82 \quad 13.88$

8. I am always looking for better ways to do things.

0.71

14.30

9. If I believe in an idea, no obstacle will prevent me from making it happen.

0.75

13.10

10. I can spot a good opportunity long before others can.

0.76

13.06

\section{OCB-Altruism}

1. I help orient new employees even though it is not required.

$0.54 \lambda$ set to 1

2. I am always ready to help or to lend a helping hand to those around me.

0.87

12.28

3. I willingly give of my time to help others.

0.88

12.27

\section{$\underline{O C B}$ - Sportsmanship}

1. I consume a lot of time complaining about trivial matters.*

2. I tend to make "mountains out of molehills" (makes problems bigger than they are).*

3. I always focus on what's wrong my situation, rather than the positive side of it.*

$0.78 \quad 20.02$

Global fit indices: $X^{2}=456.10, d f=206, p<0.001$; CFI $=0.96$, GFI $=0.92, \mathrm{AGFI}=0.90, \mathrm{SRMR}=0.05, \mathrm{RMSEA}=$ $0.05 ; *$ reverse-coded items 
Table 6

Means, Descriptive Statistics, and Correlations for Retail Employee Sample (Study 2)

\begin{tabular}{lcccccccc}
\hline Variable & M & SD & 1 & 2 & 3 & 4 & 5 & 6 \\
\hline 1. Relational Authenticity & 3.48 & 0.97 & $(0.89)$ & & & & & \\
2. OCB-Sportsmanship & 3.78 & 1.09 & $0.52^{* *}$ & $(0.88)$ & & & & \\
3. OCB-Altruism & 4.14 & 0.70 & 0.08 & -0.01 & $(0.78)$ & & & \\
4. Proactive Personality & 3.93 & 0.66 & 0.04 & $-0.14^{* *}$ & $0.49^{* *}$ & $(0.92)$ & & \\
5.Age & 39.06 & 15.41 & $0.21^{* *}$ & $0.19^{* *}$ & -0.08 & $-0.27^{* *}$ & - & \\
6. Gender & 1.70 & 0.46 & 0.05 & $0.09^{*}$ & $0.09^{*}$ & -0.06 & -0.08 & - \\
7. Tenure & 3.39 & 2.12 & -0.01 & -0.05 & -0.06 & $-0.11^{*}$ & $0.41^{* *}$ & -0.08 \\
\hline
\end{tabular}

$* \mathrm{p}<0.05$, two-tailed. $* * \mathrm{p}<0.01$, two-tailed. $\mathrm{N}=500$.

Gender was coded as $1=$ male and $2=$ female.

Cronbach's alpha is on the diagonal. 
Table 7

Convergent and Discriminant Validities for Retail Employee Sample (Study 2)

\begin{tabular}{lcccccccc}
\hline & CR & AVE & MSV & MaxR $(\mathrm{H})$ & $\begin{array}{c}\text { Proactive } \\
\text { Personality }\end{array}$ & $\begin{array}{c}\text { Relational } \\
\text { Authenticity }\end{array}$ & Sportsmanship Altruism \\
\hline Proactive Personality & 0.92 & 0.53 & 0.26 & 0.92 & 0.73 & & & \\
Relational Authenticity & 0.88 & 0.52 & 0.33 & 0.88 & 0.04 & 0.72 & 0.85 \\
Sportsmanship & 0.83 & 0.72 & 0.33 & 0.90 & -0.15 & 0.58 & 0.06 & 0.78 \\
Altruism & 0.82 & 0.61 & 0.26 & 0.88 & 0.51 & 0.13 & 0.06 \\
\hline
\end{tabular}

Note: The numbers in diagonal cells are $\sqrt{ } \mathrm{AVE} ; \mathrm{CR}=$ composite reliability, $\mathrm{AVE}=$ average variance extracted, $\mathrm{MSV}=$ maximum shared variance, $\operatorname{MaxR}(\mathrm{H})=$ maximum reliability. 
Table 8

Preacher and Hayes PROCESS Results for Retail Employee Sample (Study 2)

\begin{tabular}{|c|c|c|c|c|}
\hline & \multicolumn{4}{|c|}{ Dependent variable: Altruism } \\
\hline & $B$ & SE & LLCI & ULCI \\
\hline \multicolumn{5}{|l|}{ Controls } \\
\hline Age & $0.01 * *$ & 0.01 & 0.01 & 0.01 \\
\hline Gender & $0.12 *$ & 0.04 & 0.05 & 0.19 \\
\hline Current Job Tenure & -0.01 & 0.01 & -0.02 & 0.01 \\
\hline \multicolumn{5}{|l|}{ Main Effects } \\
\hline Relational Authenticity $(a)$ & $0.11^{*}$ & 0.03 & 0.04 & 0.17 \\
\hline Proactive Personality $(b)$ & $1.03 * *$ & 0.04 & 0.95 & 1.12 \\
\hline \multicolumn{5}{|l|}{ Two-way Interaction } \\
\hline$a \times b$ & $-0.10^{+}$ & 0.06 & -0.21 & 0.02 \\
\hline$R$ & $0.75^{* *}$ & & & \\
\hline$R^{2}$ & $0.56 * *$ & & & \\
\hline
\end{tabular}

\begin{tabular}{|c|c|c|c|c|}
\hline & \multicolumn{4}{|c|}{ Dependent variable: Sportsmanship } \\
\hline & $B$ & SE & LLCI & ULCI \\
\hline \multicolumn{5}{|l|}{ Controls } \\
\hline Age & $0.01 *$ & 0.01 & 0.01 & 0.01 \\
\hline Gender & 0.08 & 0.06 & -0.04 & 0.20 \\
\hline Current Job Tenure & -0.03 & 0.01 & -0.06 & 0.01 \\
\hline \multicolumn{5}{|l|}{ Main Effects } \\
\hline Relational Authenticity $(a)$ & $0.72 * *$ & 0.05 & 0.63 & 0.81 \\
\hline Proactive Personality $(b)$ & $0.44 * *$ & 0.11 & 0.23 & 0.64 \\
\hline \multicolumn{5}{|l|}{ Two-way Interaction } \\
\hline$a \times b$ & 0.12 & 0.10 & -0.07 & 0.32 \\
\hline$R$ & $0.66 * *$ & & & \\
\hline$R^{2}$ & $0.44 * *$ & & & \\
\hline
\end{tabular}




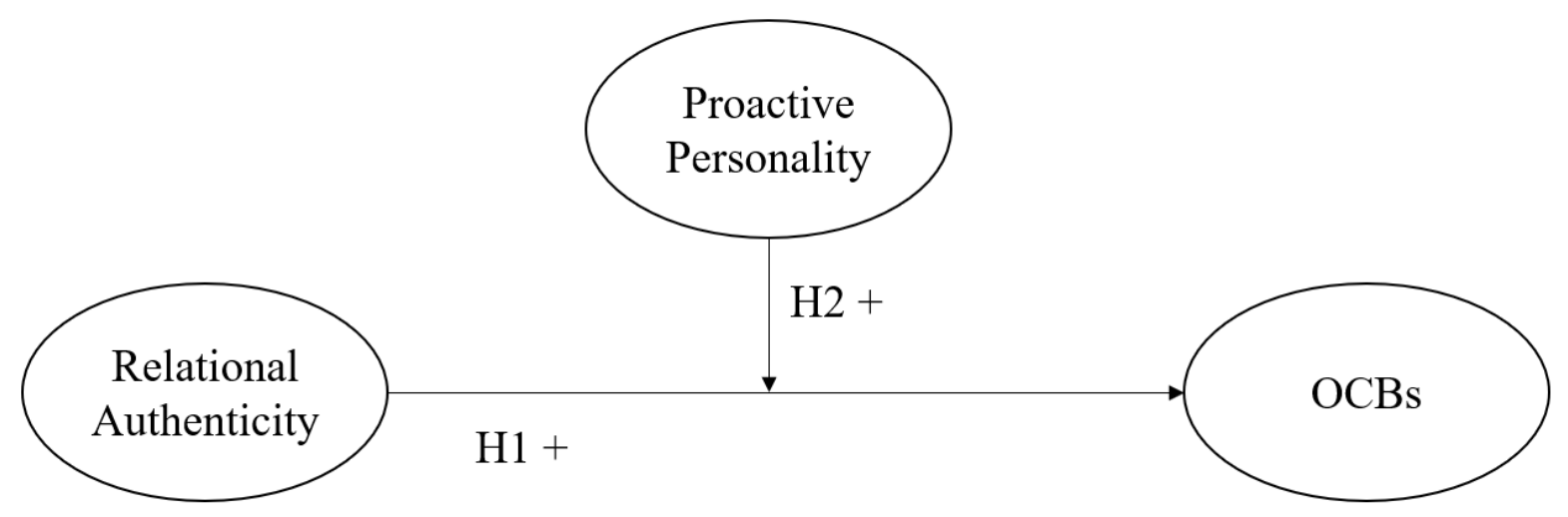

Figure 1. Graphical representation of model and hypotheses. 


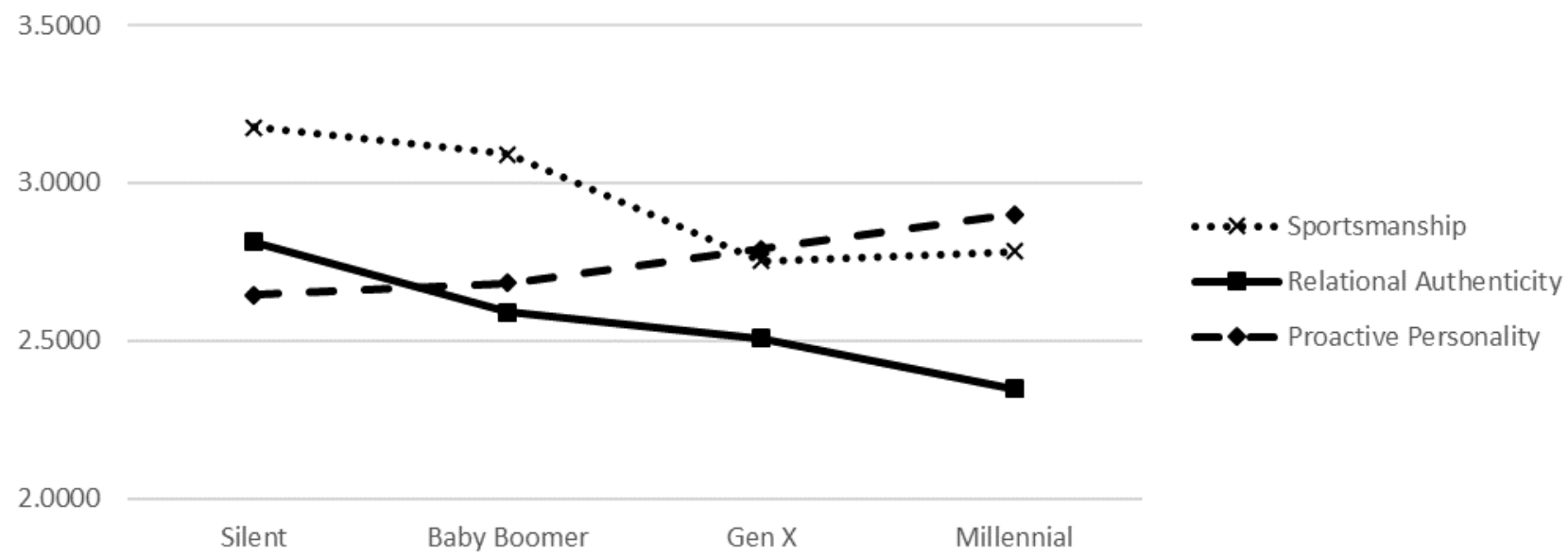

Figure 2. Mean differences between generations regarding levels of sportsmanship, relational authenticity, and proactive personality. 